
\title{
Ionic Conductivity of an Extruded Nafion 1100 EW Series of
Membranes
}

\author{
S. Slade, ${ }^{\text {a,d }}$ S. A. Campbell, ${ }^{\text {a }}$ T. R. Ralph, ${ }^{\text {b,* }}$ and F. C. Walsh ${ }^{\mathrm{c}, *, \mathrm{z}}$ \\ ${ }^{a}$ Applied Electrochemistry Group, School of Pharmacy and Biomedical Sciences, University of Portsmouth, \\ Portsmouth PO1 2DT, United Kingdom \\ ${ }^{b} J o h n s o n$ Matthey Technology Center, Reading RG4 9NH, United Kingdom \\ ${ }^{c}$ Electrochemical Engineering Group, Department of Chemical Engineering, University of Bath, \\ Bath BA2 7AY, United Kingdom
}

The proton conductivity of a series of extruded Nafion membranes [of equivalent weight (EW) of 1100 and nominal dry thickness of $51,89,127$, and $178 \mu \mathrm{m}$ ] has been studied. Measurements were made in $1 \mathrm{M} \mathrm{H}_{2} \mathrm{SO}_{4}$ at $298 \mathrm{~K}$ using a four-electrode, dc technique. The membrane area resistance increases with thickness, as expected, from 0.07 to $0.16 \Omega \mathrm{cm}^{2}$ for Nafion 112 and Nafion 117, respectively. However, in contrast to the published literature, after correcting for the membrane thickness, the conductivity of the membranes decreases with decreasing membrane thickness. For example, values of 0.083 and $0.16 \mathrm{~S} \mathrm{~cm}^{-1}$ were obtained for Nafion 112 and 117 membranes, respectively. In situ current-interrupt measurements in a proton exchange membrane fuel cell confirmed the relatively poor conductivity of the membrane electrode assemblies (MEAs) based on the thinner membranes. While a high contact resistance to the electrodes may have contributed to the in situ MEA resistance, water balance measurements over the MEA showed that the high resistance was not due to a low water content or to an uneven water distribution in the MEAs. The implications of the findings for the understanding of the membrane properties are discussed.

(C) 2002 The Electrochemical Society. [DOI: 10.1149/1.1517281] All rights reserved.

Manuscript submitted May 29, 2001; revised manuscript received June 5, 2002. Available electronically October 18, 2002.

Nafion membranes.-Nafion membranes have a wide range of applications due to their high chemical and electrochemical stability, reasonable mechanical strength (particularly when reinforced), extremely low permeability to reactant species, selective and high ionic conductivity, and their ability to provide electronic insulation. ${ }^{1}$ Industrial applications of these materials involve industrial sectors such as gas separation, gas sensors, electrodialysis, chlor-alkali cells, salt splitting, and as a solid polymer electrolyte in fuel cells and batteries. $^{2-4}$

This study has focused on the application of the Nafion range of cation-exchange membranes in proton exchange membrane fuel cells (PEMFCs). In the PEMFC the proton conductivity of the membrane is particularly important since it plays a significant role in controlling the performance of the fuel cell. ${ }^{5,6}$ Higher levels of proton conductivity allow much higher power densities to be achieved. This is particularly important for automotive applications of PEMFCs. The two common strategies to improve the conductivity of the membrane are to raise the specific conductivity and to reduce the thickness. There is, however, a practical limit on the thickness since, much below $25 \mu \mathrm{m}$, mixing of the hydrogen and air (or oxygen) reactant gasses due to crossover through the ion-exchange material is too high for pure Nafion membranes and there is a loss of efficiency. Reducing the membrane thickness also increases the risks with respect to mechanical properties such as strength, raising concerns regarding the durability and ease of handling of the membranes.

The structure of Nafion membranes.-The proton conductivity of Nafion membrane materials is complex, being favored by a high level of hydration and being strongly dependent on the pretreatment (especially the thermal) history of the membrane, the operating temperature, and the electrolyte environment. This has been rationalized by considering the complicated structure of the polymers represented by the general formula shown in Fig. 1. The values of $n, x$, and $m$ can be varied to produce materials of different equivalent weight $(\mathrm{EW})$, where $\mathrm{EW}$ is the number of grams of the polymer per

\footnotetext{
* Electrochemical Society Active Member.

${ }^{\mathrm{d}}$ Present address: Regenesys Technologies, Limited, Harwell International Business Center, Harwell, Oxon. OX11 0QA, United Kingdom.

${ }^{\mathrm{z}}$ E-mail: F.C.Walsh@bath.ac.uk
}

mole of fixed sulfonate sites. ${ }^{4}$ In this study, the EW was maintained constant at 1100, although EWs from 900 to 1400 can be manufactured.

Several models ${ }^{7-11}$ have attempted to explain the structure of Nafion. While each model has limitations, it is generally accepted that there are distinct regions within the membrane. There is a hydrophobic region containing the fluorocarbon backbone and a hydrophilic, ionic region containing the sulfonate sites, the protons, and the water of hydration. An intermediate region exists between the two phases with some of the character of both regions. The hydrophobic fluorocarbon chains and the hydrophilic sulfonate groups are arranged to maximize the interaction between the similar fragments. This is thought to result in the formation of inverted micelles or ion clusters containing the hydrated ionic phase, which are embedded in the fluorocarbon phase. It is presumed that proton transport occurs between the clusters by proton movement between the fixed sulfonate sites. A high level of hydration produces an enlarged cluster dimension, which promotes the rate of proton transport. ${ }^{8-12}$

Proton conductivity.-Many groups have previously studied the conductivity of Nafion membranes, predominantly using ac impedance spectroscopy, ${ }^{3,16-19,21-30}$ although dc techniques have also been adopted. ${ }^{14,15,20,21}$ Only one group appears to have considered both techniques in one paper. ${ }^{21} \mathrm{~A}$ few groups have looked at the performance of the membrane in situ in the PEMFC using ac impedance ${ }^{30}$ and a current pulse technique. ${ }^{31} \mathrm{~A}$ variety of environments has been employed including $1 \mathrm{M} \mathrm{H}_{2} \mathrm{SO}_{4},{ }^{14,15,21,25}$ water, ${ }^{16-19,21,22,29}$ water vapor, ${ }^{13,16-19,23,26-28}$ and humidified gases ${ }^{30,31}$ at temperatures from 20 to $95^{\circ} \mathrm{C}$.

The impact of such a wide range of factors on the conductivity of the Nafion membranes has resulted in a wide range of proton conductivities being published. This is highlighted in Table I, which presents a synopsis from the literature. The area resistance and the resistivity have also been listed in Table I since they are commonly employed in the fuel-cell literature.

The earliest data shown in Table I is that of Reike and Vanderborgh. ${ }^{13}$ Using ac impedance, they reported the conductivity of Nafion 117 in humidified nitrogen at $100 \%$ relative humidity $(\mathrm{RH})$ and $25^{\circ} \mathrm{C}$ as $0.070 \mathrm{~S} \mathrm{~cm}^{-1}$. Using a dc technique, Verbrugge et al. ${ }^{14,15}$ examined the conductivity of Nafion 117 in $\mathrm{H}_{2} \mathrm{SO}_{4}$ over a range of acid concentrations and temperatures. The conductivity was progressively promoted in the acid concentration range from 0.3 to 1 $\mathrm{M}$ but decreased at higher concentrations. In $1 \mathrm{M} \mathrm{H}_{2} \mathrm{SO}_{4}$, the con- 


\section{$\left[\left(\mathrm{CF}_{2} \mathrm{CF}_{2}\right)_{\mathrm{n}} \mathrm{CFCF}_{2}\right]_{\mathrm{x}}$ \\ $\left(\mathrm{OCF}_{2} \mathrm{CF}\right)_{\mathrm{m}} \mathrm{OCF}_{2} \mathrm{CF}_{2} \mathrm{SO}_{3} \mathrm{H}$ \\ $\mathrm{CF}_{3}$}

Figure 1. The general structure of a Nafion membrane. ${ }^{4}$

ductivity increased from 0.088 to $0.231 \mathrm{~S} \mathrm{~cm}^{-1}$ as the temperature was increased from 20 to $80^{\circ} \mathrm{C}$. Shortly after this, a series of papers by Zawodzinski et al. ${ }^{16-19}$ reported on the conductivity of Nafion 117 in an aqueous environment using ac impedance. In water at $30^{\circ} \mathrm{C}$, the reported conductivity was $0.100 \mathrm{~S} \mathrm{~cm}^{-1}$. At the higher temperature of $90^{\circ} \mathrm{C}$ this increased to $0.19 \mathrm{~S} \mathrm{~cm}^{-1}$. In humidified air at $100 \% \mathrm{RH}$ and $30^{\circ} \mathrm{C}$, in agreement with the earlier findings of Reike and Vanderborgh, ${ }^{13}$ the conductivity was significantly reduced to a value of $0.06 \mathrm{~S} \mathrm{~cm}^{-1}$.
It was argued that the process of water sorption from the vapor phase was reduced because of poor wetting of the perfluorinated pore walls in the membrane retarding condensation on the hydrophobic surface. ${ }^{17}$ It was confirmed by Reike and Vanderborgh ${ }^{13}$ and then Zawodzinski et al., ${ }^{17,18}$ that at $30^{\circ} \mathrm{C}$ the water uptake of a Nafion 117 membrane decreases from a $\lambda$ value of 22 for a fully immersed membrane in liquid water to a $\lambda$ of 14 when the membrane was suspended over humidified air at $100 \% \mathrm{RH}$. ( $\lambda$ is the ratio of the number of moles of $\mathrm{H}_{2} \mathrm{O}$ to the number of moles of $\mathrm{SO}_{3} \mathrm{H}$ ). The higher water content was considered to be the principal reason for the higher membrane conductivity in liquid water.

The significance of the electrolyte was further highlighted by Perez et al. ${ }^{20}$ and Kolde et al. ${ }^{21} \mathrm{In} 2 \mathrm{M} \mathrm{HCl}$ at $25^{\circ} \mathrm{C}$, using a dc technique, a conductivity of $0.066 \mathrm{~S} \mathrm{~cm}^{-1}$ was found for Nafion 117 by Perez et al., ${ }^{20}$ which is lower than the values suggested by the data of Verbrugge et al. ${ }^{14,15}$ in more dilute $\mathrm{H}_{2} \mathrm{SO}_{4}$ electrolytes. Supporting a higher conductivity in $\mathrm{H}_{2} \mathrm{SO}_{4}$, Kolde et al. ${ }^{21}$ found in $1 \mathrm{M}$ $\mathrm{H}_{2} \mathrm{SO}_{4}$ solution at $25^{\circ} \mathrm{C}$, ac impedance gave a much higher conductivity of $0.140 \mathrm{~S} \mathrm{~cm}^{-1}$ for Nafion 117 . In water at $25^{\circ} \mathrm{C}$ a lower value of $0.100 \mathrm{~S} \mathrm{~cm}^{-1}$ was found. ${ }^{21}$ While there is scatter in the reported conductivities, this indicated that absorption of the $\mathrm{H}_{2} \mathrm{SO}_{4}$ into the membrane does promote the conductivity of Nafion $117 .^{21}$ Presumably, in the more concentrated $\mathrm{HCl}$ solution used by Perez et al.,${ }^{20}$ the acid dissociation was reduced; rather than promoting the

Table I. Conductivity measurements on Nafion 1100 EW membranes.

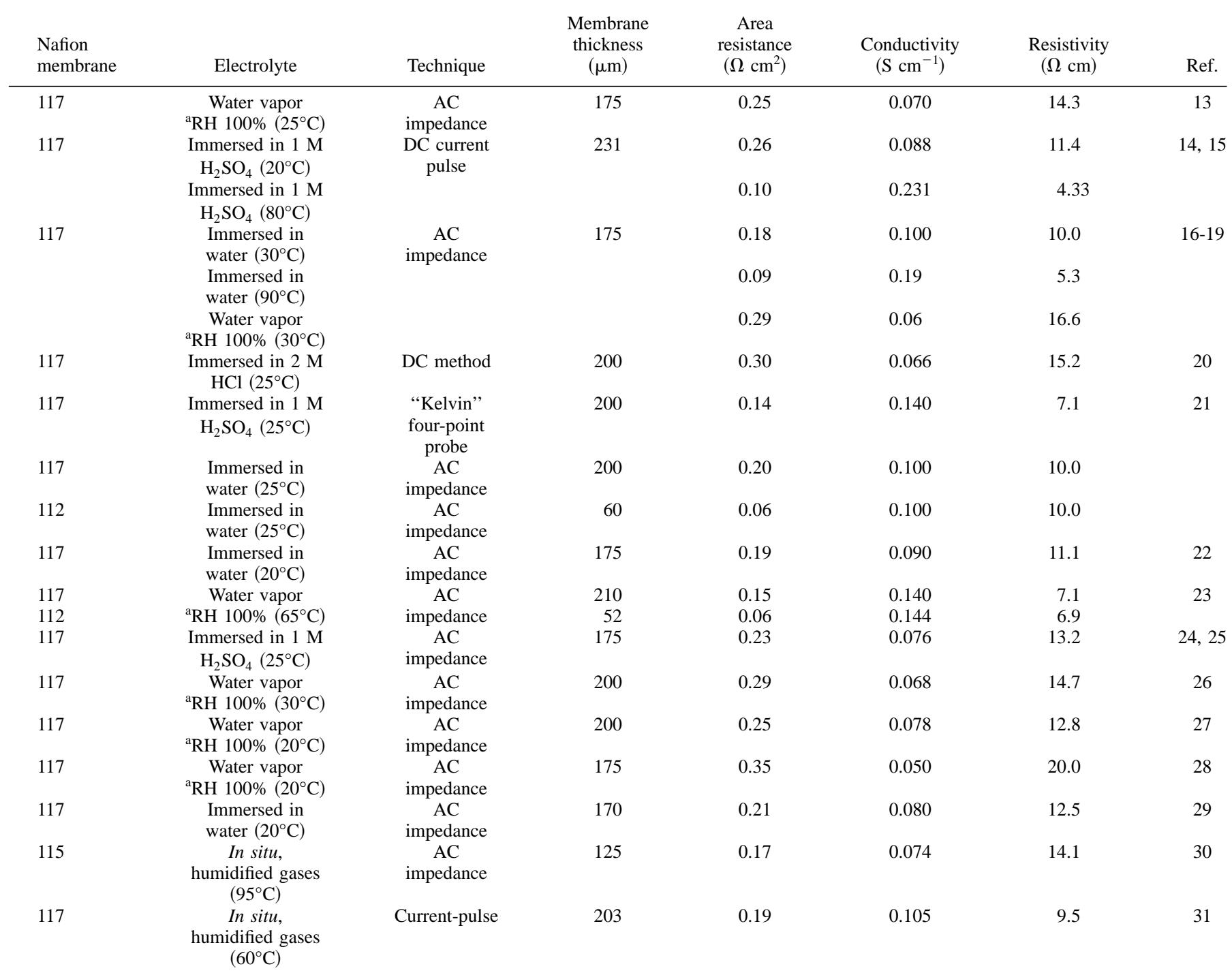


membrane conductivity the incorporated acid lowered the proton conductivity.

The remaining ex situ conductivities reported in Table I highlight the significant scatter in the quoted conductivities of Nafion 117, even in the same electrolyte in a narrow temperature range. In liquid water, conductivities of $0.090 \mathrm{~S} \mathrm{~cm}^{-122}$ and $0.080 \mathrm{~S} \mathrm{~cm}^{-129}$ were recorded. A higher value of $0.100 \mathrm{~S} \mathrm{~cm}^{-1}$ was published for the conductivity of Nafion 117 measured at $30^{\circ} \mathrm{C}^{16-19}$ and $25^{\circ} \mathrm{C} .{ }^{21}$

In $1 \mathrm{M} \mathrm{H}_{2} \mathrm{SO}_{4}$ at $25^{\circ} \mathrm{C}$, Yoshitake et al. ${ }^{24,25}$ obtained a much lower conductivity of $0.076 \mathrm{~S} \mathrm{~cm}^{-1}$ than the $0.088 \mathrm{~S} \mathrm{~cm}^{-1}$ value reported by Verbrugge et al. at $20^{\circ} \mathrm{C}^{14,15}$ Conflicting with both these values is the conductivity of $0.140 \mathrm{~S} \mathrm{~cm}^{-1}$ reported at $25^{\circ} \mathrm{C}$ by Kolde et $a l .^{21}$

In humidified air $(100 \% \mathrm{RH})$ a conductivity of $0.068 \mathrm{~S} \mathrm{~cm}^{-1}$ was measured by Antantaramen and Gardner at $30^{\circ} \mathrm{C} .^{26}$ This contrasts with the slightly higher conductivity of $0.070 \mathrm{~S} \mathrm{~cm}^{-1}$ reported by Reike and Vanderborgh ${ }^{13}$ in humidified nitrogen at $100 \%$ RH at the lower temperature of $25^{\circ} \mathrm{C} .{ }^{13} \mathrm{~A}$ further reduction in temperature to $20^{\circ} \mathrm{C}$ resulted in higher reported conductivities of $0.078 \mathrm{~S} \mathrm{~cm}^{-1}$ by Sone $e a_{a l}{ }^{27}$ and of $0.080 \mathrm{~S} \mathrm{~cm}^{-1}$ by Sumner et al. ${ }^{28} \mathrm{~A}$ significant increase in the temperature to $65^{\circ} \mathrm{C}$ did, however, result in a much higher conductivity of $0.140 \mathrm{~S} \mathrm{~cm}^{-1}$ in humidified air at $100 \%$ $\mathrm{RH}^{23}$

Much of the scatter in the published conductivities probably reflects the importance of the handling and pretreatment of the membrane in determining the water content, and therefore, the proton conductivity of Nafion membranes. Some of the differences in conductivity reflect the use of various experimental techniques.

The dependence of the water uptake from the liquid phase on the pretreatment of the membrane was mentioned in the earliest descriptions of Nafion properties. Grot et al. ${ }^{32}$ first noted that Nafion membranes take up a lot more liquid water at very high temperatures, which causes the membranes to swell as the inverted micelles or ion clusters grow due to the water uptake. If the polymer is subsequently cooled, the polymer maintains the swollen state brought about by the high water uptake into the ionic cluster phase. Subsequent immersion in liquid water at temperatures at or below the pretreatment temperature results in the Nafion membranes retaining the high water content. In contrast, shrunken membranes with reduced ion cluster dimensions can be achieved by drying the membranes completely at elevated temperatures. The ionic clusters can shrink and freeze in the shrunken state on subsequent cooling. ${ }^{12}$ The membranes then contain less water than a membrane that has not been dried at elevated temperatures.

Zawodzinski et al. ${ }^{17,18}$ investigated this phenomenon for Nafion 117. It was confirmed that the water content of Nafion 117 pretreated at high temperature to swell the membrane, with subsequent drying at room temperature under vacuum for $24 \mathrm{~h}$, produced a membrane with a high $\lambda$ of 21 upon reimmersion in liquid water. Further the $\lambda$ value was independent of the water temperature from room temperature to boiling point. Extended drying of the Nafion 117 membrane after the $24 \mathrm{~h}$ under vacuum for $1 \mathrm{~h}$ at $105^{\circ} \mathrm{C}$ resulted in a significantly reduced $\lambda$ value of 12 upon reimmersion in liquid water at $27^{\circ} \mathrm{C}$. Increasing the water temperature to $80^{\circ} \mathrm{C}$ produced an increase in the $\lambda$ value to 16 . In this case, the drying treatment did not result in a completely irreversible shrinkage of the ion clusters in the Nafion 117 membrane but produced a lower water content. Such membrane pretreatment would decrease the membrane performance in the PEMFC.

Kreuer et al. ${ }^{33}$ have shown that at reduced water contents $(\lambda<12)$ the proton mobility in the hydrophilic nanopores of Nafion is very similar to the mobility of water. At higher water levels (such as a $\lambda$ value of 22) proton hopping was much more significant and the ratio of proton to water movement increased to 2.5. Further increases in the water level, by boiling the membranes in glycerol, did not lead to enhanced proton diffusion but lowered the conductivity. This was attributed to restricted mobility of the fluorocarbon side chain limiting the degree of proton hopping between the fixed sulfonate sites. It was argued that this pretreatment is, therefore, unlikely to produce increased fuel-cell performance. This suggests a $\lambda$ value close to 22 is likely to represent nearoptimum conditions in terms of the maximum proton conductivity from the extruded Nafion membranes in the PEMFC.

Kreuer et al. ${ }^{33}$ further stressed the significance of the phase separation in Nafion in providing a better-connected hydrophilic network within the ionomer for enhanced proton diffusion. Based on a comparison with a homogeneously sulfonated polyaromatic ionomer, which does not show phase separation, it was shown that the phase separation in the Nafion membrane produced an order of magnitude enhancement in both proton and water mobility. ${ }^{33}$ Clearly, the membrane pretreatment is important in determining both the water uptake and the proton conductivity of Nafion membranes.

There has been relatively little published information concerning the proton conductivity in the PEMFC environment as shown in Table I. Wakizoe et al. ${ }^{30}$ employed ac impedance to yield a conductivity of $0.074 \mathrm{~S} \mathrm{~cm}^{-1}$ for Nafion 115 at a fuel-cell operating temperature of $95^{\circ} \mathrm{C}$. Buchi and Scherer ${ }^{31}$ looked at Nafion 117 and measured a conductivity of $0.104 \mathrm{~S} \mathrm{~cm}^{-1}$ at $60^{\circ} \mathrm{C}$ using the currentpulse method with the single cell operating at $500 \mathrm{~mA} \mathrm{~cm}{ }^{-2}$. The thicker Nafion 117 membrane provided a higher conductivity at a much lower operating temperature of $60^{\circ} \mathrm{C}$ compared with the conductivity of Nafion 115 measured at $95^{\circ} \mathrm{C}$. This may reflect the difficulty in isolating membrane resistance from the total resistance.

Investigation of membrane thickness.-While reducing the membrane thickness is a common strategy to improve the performance of PEMFCs, Table I shows that very few papers have considered the proton conductivity of Nafion membranes of varying thickness. ${ }^{21,23}$ Kolde et al. ${ }^{21}$ found (using ac impedance) that for Nafion 117 (200 $\mu \mathrm{m})$ and Nafion $112(60 \mu \mathrm{m})$ the proton conductivity of the membranes immersed in water was $0.100 \mathrm{~S} \mathrm{~cm}^{-1}$, this value being independent of the membrane thickness. This trend was also found by Nouel and Fedkiw, ${ }^{23}$ but this time in air at $100 \% \mathrm{RH}$ and $65^{\circ} \mathrm{C}$. Again using ac impedance, conductivities of 0.140 and $0.144 \mathrm{~S}$ $\mathrm{cm}^{-1}$ were reported for Nafion $117(210 \mu \mathrm{m})$ and Nafion $112(52$ $\mu \mathrm{m})$. Considering the experimental accuracy, this again reflects the independence of the conductivity on the membrane thickness as expected for materials that show ohmic behavior.

Here, a specific range of extruded Nafion membranes was examined using the commercially available extruded membranes from DuPont, i.e., Nafion $112(51 \mu \mathrm{m})$, Nafion 1135 (89 $\mu \mathrm{m})$, Nafion 115 $(127 \mu \mathrm{m})$, and Nafion $117(178 \mu \mathrm{m})$. A four-electrode, dc technique was employed using membrane potential measurements to determine membrane resistances and hence proton conductivities in a 1.0 $\mathrm{M} \mathrm{H}_{2} \mathrm{SO}_{4}$ electrolyte at $25^{\circ} \mathrm{C}$ using a galvanodynamic technique. These studies were allied to measurement of the MEA resistances in the PEMFC environment at $80^{\circ} \mathrm{C}$ using the current-interrupt technique. ${ }^{34,35}$ This has allowed a determination of the proton conductivity of a series of Nafion membranes of varying thickness (but constant equivalent weight and fixed hydration) in these two different environments.

\section{Experimental}

Membrane preparation.- The range of commercially available extruded membranes (of nominal equivalent weight 1100) was obtained from DuPont, i.e., Nafion 112, Nafion 1135, Nafion 115, and Nafion 117 in the $\mathrm{H}^{+}$form.

Historically, it has been normal practice in PEMFC studies to pretreat Nafion membranes to ensure purity and full hydration. $1,12,36$ Accordingly, all membranes were pretreated by heating to $80^{\circ} \mathrm{C}$ in $2 \%$ by volume $\mathrm{H}_{2} \mathrm{O}_{2}$ (Fisher Scientific, AnalaR grade) for $2 \mathrm{~h}$, followed by cooling and rinsing in doubly distilled water. The membranes were then soaked in $0.5 \mathrm{M} \mathrm{H}_{2} \mathrm{SO}_{4}$ (Fisher Scientific, AnalaR grade) for $48 \mathrm{~h}$, rinsed in doubly distilled water, and boiled in 0.02 $\mathrm{M} \mathrm{H}_{2} \mathrm{SO}_{4}$ for $1 \mathrm{~h}$. After further rinsing in doubly distilled water to remove the final traces of acid, the membranes were stored in doubly distilled water until required. The conductivity of the storage 
water was measured prior to usage of the membranes to ensure it remained below $0.1 \mu \mathrm{S} \mathrm{cm} \mathrm{cm}^{-1}$.

Membrane thickness. - Both the dry and the hydrated membrane thickness were measured at 20 random points over their surface to $\pm 1 \mu \mathrm{m}$ using a digital micrometer (Mitutoyo, digimatic micrometer). Care was taken to ensure that the micrometer jaws did not compress the membrane during thickness measurements.

The membrane thickness in the membrane electrode assemblies (MEAs) employed in the PEMFC was measured after testing in the Ballard Mark 5E single cell, using electron probe microanalysis (EPMA). A metal template and scalpel were used to cut $23 \times 14 \mathrm{~mm}$ sections from the MEA and multiple sections were taken to confirm reproducibility. Each section was placed in a fanfolded section of paper and the unit placed edge up in a $25.4 \mathrm{~mm}$ diam nylon mold. The mold was then placed in a dessicator cabinet for $24 \mathrm{~h}$ to dry. Epoxy resin (Struers) was poured into the mold to cover the upper edge of the section. Resin impregnation and air removal was promoted by placing the mold in a vacuum chamber and then in a pressure chamber set to $700 \mathrm{kPa}$ abs (absolute). The resin was allowed to set for $24 \mathrm{~h}$ under this pressure. The sample was removed from the mold and the two faces ground flat with 500 and then 1200 grit silicon carbide (SiC) paper. During this stage the MEA edges were replenished to remove any damage caused by the cutting. The sample edges were then polished using 6 and then $1 \mu \mathrm{m}$ diamond pastes lubricated with an alcohol-based polishing fluid. Copious washing with distilled water removed any traces of the polishing fluid. In some cases, moisture seeped from the membrane of the MEAs after the grinding with 500 grit $\mathrm{SiC}$ paper. When this occurred, the sample was placed in a vacuum oven at $60^{\circ} \mathrm{C}$ for $4 \mathrm{~h}$ before further grinding and polishing. Finally, a carbon film (of approximately $20 \mathrm{~nm}$ thickness) was applied to a dried, polished face of the sample using a vacuum evaporation chamber.

The sample was loaded into the EPMA analysis chamber of a Cameca SX51 machine which was controlled with a Sun Sparc Station 5. Both secondary electron (SE) and backscattered electron (BSE) images were recorded (typically at from 88 to 500 times magnification) with a time frame of $1 \times 20 \mathrm{~s}$ and an accelerating voltage of $15 \mathrm{kV}$ (SE) or $20 \mathrm{kV}$ (BSE) and a beam current of $4 \mathrm{nA}$. For the determination of $\mathrm{Pt}, \mathrm{S}$, and $\mathrm{F}$, spectral scans, and line profiles, the beam current was increased to $20 \mathrm{nA}$ using dwell times at each point of 1-2 s. For the line scans, both peak and background signals were acquired to produce a peak-background-corrected profile for each element.

Proton conductivity measurements.-Ex situ conductivity in $\mathrm{H}_{2} \mathrm{SO}_{4}$.-Figure 2 shows a schematic of the glass cell used to measure the membrane potential difference as a function of the current density flowing between the two platinum gauze electrodes placed on either side of the membrane. The platinum electrodes were connected to a potentiostat/galvanostat (Autostat, Sycopel), and a waveform generator (PPR1, Hi-Tek) was used to perform linear galvanodynamic current sweeps between 0 and $1000 \mathrm{~mA} \mathrm{~cm}^{-2}$. The current was swept from $0 \mathrm{~mA} \mathrm{~cm}^{-2}$ (at the rest potential of the membrane) to give both negative and positive membrane potential differences. This corresponded to changing the direction of the current flow through the membrane and alternating between hydrogen evolution and oxygen evolution at each of the platinum electrodes. The net cell reaction was water electrolysis to produce hydrogen and oxygen (at the cathode and anode, respectively) from the $1.0 \mathrm{M} \mathrm{H}_{2} \mathrm{SO}_{4}$ electrolyte. The electrolyte was maintained at $25^{\circ} \mathrm{C}$ by immersing the glass cell in a thermostatic water bath (Otecam bath with a Techne fail safe Tempunit). By communicating two (closely matched) saturated calomel reference electrodes (SCE, Radiometer Ref 401, Radiometer, Ltd., Crawley, West Sussex, U.K.) to a fixed distance from either face of the membrane using Luggin capillaries, it was possible to measure the potential difference between the SCEs with a high-impedance digital voltmeter (Thandar TM451) connected to the SCEs. The accuracy of placement of the Luggin capillaries was carefully checked by measuring the gap between the

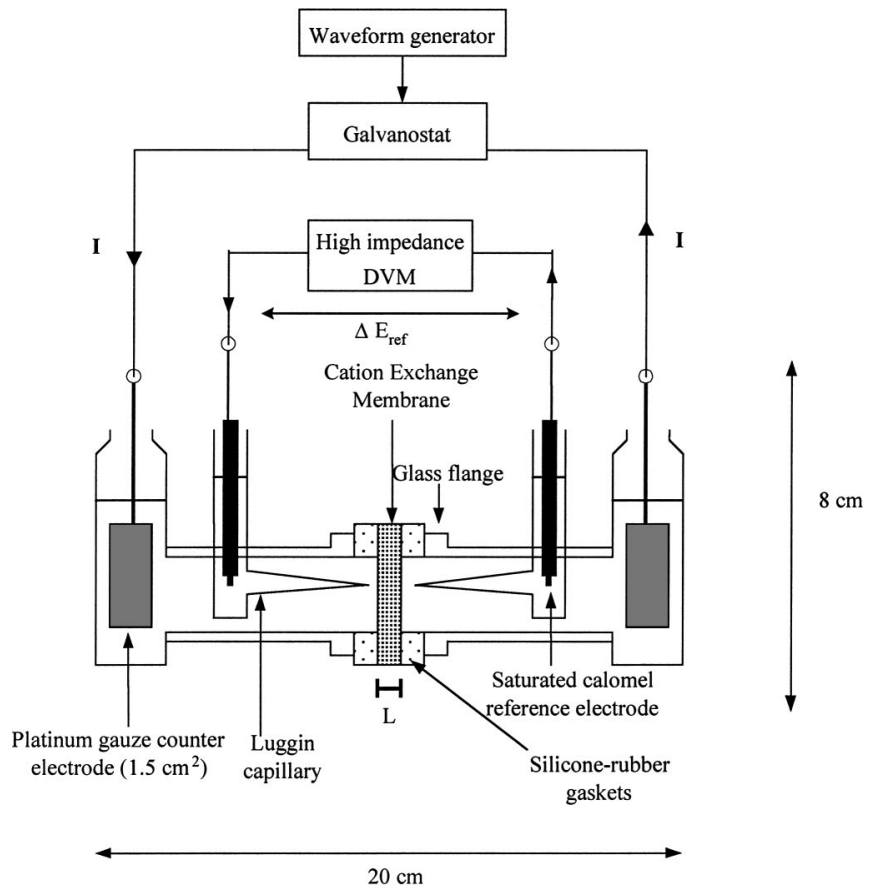

Figure 2. Schematic of the four-electrode glass cell used for conductivity measurements on a circular sample $\left(1 \mathrm{~cm}^{2}\right)$ of membrane, using a steadystate linear sweep galvanodynamic technique.

Luggin tip and the membrane surface using a vernier gauge. The identical distance of $1.5 \mathrm{~mm}$ between the Luggin capillary tip and the membrane surface, with different thicknesses of membrane, was achieved by altering the thickness of the flange gaskets. Great care was taken to ensure the flange defined an active membrane area of $1 \pm 0.025 \mathrm{~cm}^{2}$ and that the gasket material did not impinge on the membrane in the open flange area.

Plots of the potential difference between the SCEs vs. the current obeyed Ohm's Law (i.e., $\Delta E_{\text {ref }}=I R_{\text {cell }}$ ) over a wide range of membrane current density. This allowed the average cell resistance to be determined from the slope of the line. The membrane resistance was then obtained from the cell resistance by measuring the corresponding cell resistance in the absence of the membrane (i.e., $\left.\Delta E_{\text {ref }}=I R_{\text {electrolyte }}\right)$. This gave the background electrolyte resistance which was subtracted from the cell resistance to give the membrane resistance (i.e., $R_{\text {mem }}=R_{\text {cell }}-R_{\text {electrolyte }}$ ). This background electrolyte resistance accounted for some $60-80 \%$ of the cell resistance. This is a significant correction and is the major reason why such great care is required in these measurements. The membrane resistance was then used to calculate the area resistance (i.e., $R_{\mathrm{A}}=R_{\mathrm{mem}} A$ ), the resistivity (i.e., $\rho=R_{\mathrm{A}} / L$ ), and the conductivity (i.e., $\mathrm{\kappa}=L / R_{\mathrm{A}}$ ) of the membranes.

In situ conductivity in the PEMFC.-Cathodes and anodes were screen printed onto a Toray TGP-090 carbon paper substrate (Toray Industries, Chuo-ku, Tokyo, Japan) using aqueous Nafion catalyst inks $^{37}$ and the Johnson Matthey carbon-supported catalysts, HiSpec 4000 (40 wt \% Pt on Vulcan XC72R carbon black) and HiSpec 5000 (20 wt \% Pt, 10 wt \% Ru on Vulcan XC72R), respectively. Electrode platinum loadings of $0.7 \mathrm{mg} \mathrm{Pt} \mathrm{cm}{ }^{-2}$ on the cathode and $0.25 \mathrm{mg} \mathrm{Pt}$ $\mathrm{cm}^{-2}$ on the anode were employed.

MEAs were manufactured from the electrodes and the Nafion membranes (DuPont, Fayetteville, NC) by hot-pressing at pressures close to $2.8 \mathrm{MPa}$ abs over the MEA and at temperatures above the glass transition temperature of the membranes. All membranes were pretreated as described previously.

The MEAs were evaluated in an internally humidified Ballard Mark 5E single cell $\left(240 \mathrm{~cm}^{2}\right.$ active area $)$ which has been de- 
scribed elsewhere. ${ }^{6,34,38}$ A purpose built, Johnson Matthey test stand provided accurate control of the hydrogen and air (or oxygen) gas pressures and gas flow rates. The test stand also allowed the regulation of temperature and flow rate of the deionized water used to control the single cell temperature and to provide the reactant gas humidification.

The MEA was conditioned at $538 \mathrm{~mA} \mathrm{~cm}^{-2}$ under the selected operating conditions [i.e., $T_{\text {in }}$ (for cell) at $80^{\circ} \mathrm{C}, \mathrm{H}_{2} /$ air at $304 / 304$ $\mathrm{kPa}$ abs and 1.5/2.0 stoichiometry]. After conditioning of the membranes, the steady-state cell potential vs. current density performance was recorded galvanostatically at the selected gas stoichiometries. The current was allowed to stabilize for $15 \mathrm{~min}$ at each load. The oxidant was changed to oxygen and the steady-state cell potential vs. current density performance measured using the same gas flow rates employed with air. This corresponded to a gas stoichiometry of 10.0 with oxygen. In the case of oxygen, only 3 min was required at each current density to stabilize the performance. During the measurement of the oxygen polarization curve the currentinterrupt technique was employed to measure the membrane resistance. At each current density, after the performance had stabilized and had been recorded, the load bank was switched to open circuit using a hexfet arrangement. The voltage decay transient was monitored on an oscilloscope (Textronics, Wilsonville, OR) using a fast sampling time of less than $50 \mu$ s to separate the ohmic and capacitive contributions to the voltage decay.

The electronic resistance of the Ballard Mark 5E carbon flow field plate, sandwiched between two sections of Toray TGP-090 carbon paper at the cathode and anode, was determined using a Solatron 7081 precision voltmeter and a two-point probe. The assembly was located between the gold-coated probe heads $\left(2 \mathrm{~cm}^{2}\right)$, with the sections of Toray paper cut to the exact dimensions of the probe heads. The probe heads were compressed onto the resultant sandwich and the compression was increased from 140 to $1200 \mathrm{kPa}$ abs and back to $140 \mathrm{kPa}$ abs to check for hysteresis.

Ion-exchange capacity and equivalent weight measurements.-Membrane samples pretreated as described previously and of measured weight $(c a .1 \pm 0.0010 \mathrm{~g})$ were placed in $50 \mathrm{~cm}^{3}$ of $0.1 \mathrm{M} \mathrm{NaCl}$ solution (BDH, AnalaR grade) for $24 \mathrm{~h}$ to convert the membrane from the $\mathrm{H}^{+}$to the $\mathrm{Na}^{+}$form. The membrane samples were then removed and dried over $\mathrm{P}_{2} \mathrm{O}_{5}(\mathrm{BDH}$, SLR grade) in a closed container, at room temperature, for $48 \mathrm{~h}$. The $\mathrm{NaCl}$ solution was titrated against $0.02 \mathrm{M} \mathrm{NaOH}(\mathrm{BDH}$, AnalaR grade) to an end point at $\mathrm{pH} 7.0$ using phenol red indicator solution (Aldrich). The volume of $\mathrm{NaOH}$ consumed was used to calculate the moles of $\mathrm{H}^{+}$ in solution. Assuming complete conversion of the membrane to the $\mathrm{Na}^{+}$form, the ion-exchange capacity (IX, mol H${ }^{+} / \mathrm{g}$ polymer) and the EW, which is the reciprocal of the $I X$, was calculated via the relationship ${ }^{4,39}$

$$
I X=V_{\mathrm{NaOH}}-\frac{m_{\mathrm{NaOH}}}{M}
$$

Water content.-The samples of membrane were carefully blotted dry of all surface moisture and weighed $( \pm 0.0001 \mathrm{~g})$. Membranes were then dried over $\mathrm{P}_{2} \mathrm{O}_{5}(\mathrm{BDH}$, SLR grade) at room temperature in a sealed container for $48 \mathrm{~h}$ and then reweighed. It has been demonstrated that drying membranes over $\mathrm{P}_{2} \mathrm{O}_{5}$ at room temperature results in complete dehydration of the membrane. ${ }^{18}$ The water content of the membranes, $\lambda$, was calculated using the expression

$$
\lambda=\operatorname{EW}\left(\frac{M_{1}-M}{M_{\mathrm{H}_{2} \mathrm{O}}}\right) M
$$

\section{Results and Discussion}

Membrane thickness.-Table II shows the nominal (as supplied), dry, and hydrated thickness for the range of Nafion membranes mea-

\begin{tabular}{|c|c|c|c|c|}
\hline \multicolumn{5}{|c|}{$\begin{array}{l}\text { Table II. Nominal thickness of Nafion } 1100 \mathrm{EW} \text { membranes in } \\
\text { dry, hydrated, and MEA form. }\end{array}$} \\
\hline $\begin{array}{l}\text { Nafion } \\
\text { membrane } \\
\text { (extruded) }\end{array}$ & $\begin{array}{l}\text { Nominal } \\
\text { thickness } \\
(\mu \mathrm{m})\end{array}$ & $\begin{array}{c}\text { Dry } \\
\text { thickness } \\
(\mu \mathrm{m})\end{array}$ & $\begin{array}{c}\text { Hydrated } \\
\text { thickness } \\
(\mu \mathrm{m})\end{array}$ & $\begin{array}{l}\text { MEA membrane } \\
\text { thickness } \\
(\mu \mathrm{m})\end{array}$ \\
\hline 117 & 178 & $183 \pm 3$ & $208 \pm 5$ & $148 \pm 2$ \\
\hline 115 & 127 & $141 \pm 3$ & $161 \pm 3$ & $100 \pm 2$ \\
\hline 1135 & 89 & $91 \pm 2$ & $111 \pm 2$ & $75 \pm 3$ \\
\hline 112 & 51 & $50 \pm 2$ & $58 \pm 3$ & $40 \pm 2$ \\
\hline
\end{tabular}
sured using the micrometer. In the case of the hydrated thickness, this is the measured value after the pretreatment in $\mathrm{H}_{2} \mathrm{O}_{2}, \mathrm{H}_{2} \mathrm{SO}_{4}$, and water normally employed in PEMFC studies described previously. The Nafion membranes swell not only in the $x-y$ plane ${ }^{4}$ but also in thickness by 14 to $22 \%$ after hydration. This shows the importance of employing the hydrated thickness to calculate the conductivity and the resistivity of the membranes from the ex situ membrane resistance measurements in $1.0 \mathrm{M} \mathrm{H}_{2} \mathrm{SO}_{4}$. Table II also confirms that treating the membranes with $\mathrm{P}_{2} \mathrm{O}_{5}$ does completely dehydrate the membranes, because the dry membrane thickness is generally in good agreement with the nominal thickness values. The discrepancy of $9 \%$ in the dry and nominal thickness of Nafion 115 probably reflects some variability in the extruded product in this specific case.

In the case of the membrane thickness in the MEAs, the results of the EPMA measurements are also presented in Table II. The F line scan was principally employed to determine the membrane thickness. Because $\mathrm{F}$ was also present in the electrodes (the signal being much lower because of the much lower Nafion concentration in the electrodes), the Pt signal was employed to provide an accurate subtraction of the electrode thicknesses. This shows that as a result of the hot-pressing, the Nafion membranes are thinned by 16 to $22 \%$. The membranes are dehydrated during hot-pressing. During single-cell testing the membranes do rehydrate but they do not change thickness because they are fixed by the cathode and anode to which they are bonded. The EPMA thicknesses are, therefore, representative of the membrane thicknesses in the MEAs during singlecell testing.

Ex situ membrane conductivity in $\mathrm{H}_{2} \mathrm{SO}_{4}$. - Figure 3 shows the plot of area resistance $v s$. hydrated membrane thickness for the range of Nafion membranes. This shows the area resistance increases as the membrane thickness is increased. The increase is not

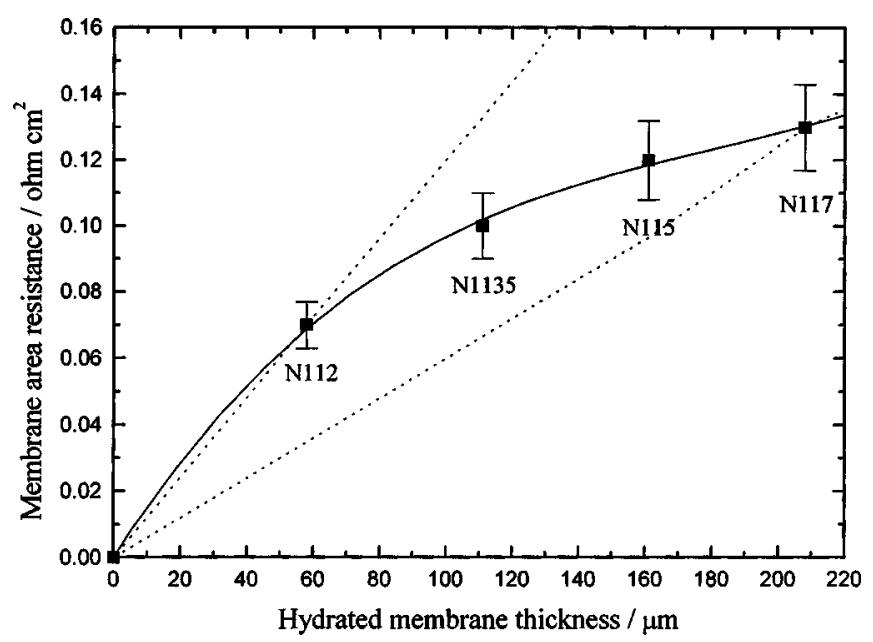

Figure 3. The variation in the area resistance of the Nafion $1100 \mathrm{EW}$ series of membranes as a function of hydrated membrane thickness in $1 \mathrm{M} \mathrm{H}_{2} \mathrm{SO}_{4}$ electrolyte at $25^{\circ} \mathrm{C}$. The upper and lower dotted lines represent the projected ohmic behavior based on N112 and N117, respectively. 


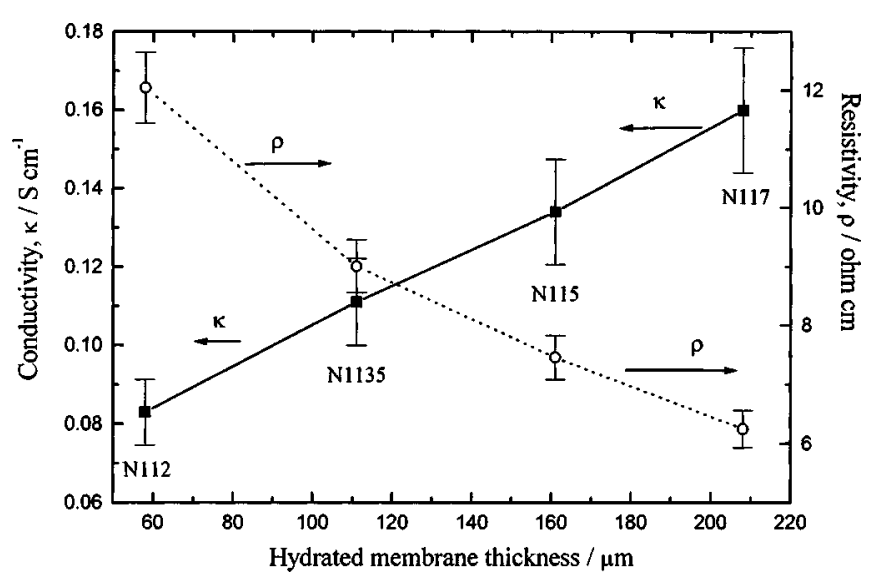

Figure 4. The variation in the conductivity and resistivity of the Nafion $1100 \mathrm{EW}$ series of membranes with hydrated membrane thickness in $1 \mathrm{M}$ $\mathrm{H}_{2} \mathrm{SO}_{4}$ at $25^{\circ} \mathrm{C}$.

linear as expected for an ohmic conductor. Rather, based on the area resistance of Nafion 117, the area resistance of the thinner membrane materials becomes progressively higher than the values predicted by a simple Ohm's Law type behavior, as shown by the dotted lines in Fig. 3. This is highlighted more clearly by presenting the data in the form of the conductivity and resistivity vs. the hydrated membrane thickness (Fig. 4). For an ohmic conductor, a horizontal line reflecting the independence of the conductivity or resistivity with sample thickness is predicted. As shown clearly in Fig. 4, the Nafion membranes do not show such independence under the experimental conditions. The lower conductivity and higher resistivity of the thinner Nafion membrane materials is clear. This is in direct contrast to the limited published literature. ${ }^{21,23}$ Comparing the conductivities with those in Table I for Nafion 117 in $1 \mathrm{M} \mathrm{H}_{2} \mathrm{SO}_{4}$ at $25^{\circ} \mathrm{C}$ shows, however, good agreement with Kolde et al. ${ }^{21}$ and values much higher than reported by Yoshitake et al. ${ }^{24,25}$ for this particular membrane. The conductivity values measured in this work are of the expected order of magnitude for DuPont's extruded membrane materials.

To ensure that the results were not due to a poor hydration of the membranes (which was unlikely in the $1.0 \mathrm{M} \mathrm{H}_{2} \mathrm{SO}_{4}$ ), the water content was determined before and after the membrane resistance measurements. This required predetermination of the ion-exchange capacity and EW of each membrane. Table III shows that the EWs are all a little lower than the specification of 1100 , with the values ranging from 1010 to 1075 . Using these EW values, the water content of the membranes after the pretreatment was measured. Table III shows the values in water (the membrane storage solution) were high, ranging from 20.7 to 23.2 . Zawodzinski et al. ${ }^{16-19}$ have shown that a $\lambda$ value of 22 represents a fully hydrated Nafion membrane. These values correspond to full hydration of the membrane. Following the resistance measurements, the corresponding values in the 1.0 $\mathrm{M} \mathrm{H}_{2} \mathrm{SO}_{4}$ electrolyte employed in the studies was determined. Table III shows the $\lambda$ values are still high (although they are slightly lower than in the storage solution), ranging from 15.5 to 19.1 . This probably reflects the effect of the $\mathrm{H}_{2} \mathrm{SO}_{4}$ present in the membrane reducing the water activity in the membrane, an effect that has been reported previously. ${ }^{40}$ Most importantly, the $\lambda$ values confirm that the membranes are close to full hydration during the membrane resistance measurements.

It is also worth noting that an uneven water distribution in the membrane is unlikely to be the cause of the lower conductivity or higher resistivity of the thinner Nafion membranes. An uneven water distribution could be attributed to a low electro-osmotic drag from the anode to the cathode or to a sluggish rate of water back-diffusion from the cathode to the anode chamber. If the electro-osmotic drag is reduced, this effect should be largely independent of the mem-

\begin{tabular}{|c|c|c|c|c|}
\hline \multicolumn{5}{|c|}{$\begin{array}{l}\text { Table III. EW and water content of the Nafion } 1100 \mathrm{EW} \text { mem- } \\
\text { branes. }\end{array}$} \\
\hline $\begin{array}{l}\text { Nafion } \\
\text { membrane } \\
\text { (Extruded) }\end{array}$ & EW & $\begin{array}{c}\lambda \\
\left(\mathrm{H}_{2} \mathrm{O} \text { at } 25^{\circ} \mathrm{C}\right)\end{array}$ & $\begin{array}{c}\lambda \\
\left(\mathrm{H}_{2} \mathrm{SO}_{4} \text { at } 25^{\circ} \mathrm{C}\right)\end{array}$ & $\begin{array}{c}\lambda \\
\left(\mathrm{H}_{2} \mathrm{O} \text { at } 80^{\circ} \mathrm{C} \text {; }\right. \\
\text { hot-pressed })\end{array}$ \\
\hline 117 & 1075 & $23.2 \pm 0.4$ & $19.1 \pm 0.6$ & $16.3 \pm 0.5$ \\
\hline 115 & 1010 & $21.9 \pm 0.6$ & $18.8 \pm 0.3$ & $15.8 \pm 0.4$ \\
\hline 1135 & 1020 & $21.1 \pm 0.6$ & $18.3 \pm 0.4$ & $14.9 \pm 0.4$ \\
\hline 112 & 1020 & $20.7 \pm 0.5$ & $15.5 \pm 0.1$ & $14.1 \pm 0.5$ \\
\hline
\end{tabular}

brane thickness. If the back-diffusion of water is sluggish, the effect would be diminished with thinner membranes and they would show a relatively higher conductivity than the thicker membranes in this situation.

In situ membrane resistance in the PEMFC.-The unexpected response of the Nafion membranes was investigated in the PEMFC using a typical MEA construction employed by Johnson Matthey. During conditioning of the MEAs at a current density of $538 \mathrm{~mA}$ $\mathrm{cm}^{-2}$, the performance gradually increased. Generally, a period of $24 \mathrm{~h}$ was required to maximize the performance. This was not due to the sluggish rehydration of the membrane; current-interrupt measurements, which do not measure the bulk electrode resistance, ${ }^{41}$ confirmed this was essentially complete within $5 \mathrm{~min}$. Rather, it reflected the time required to rehydrate the aqueous Nafion polymer present in the catalyst layer.

An indication of the effect of the MEA lamination conditions on the membranes was provided by water content measurements. The water content of hot-pressed membranes upon reimmersion in liquid water at $80^{\circ} \mathrm{C}$ is given in Table III. While this may not entirely represent the water content of the membranes during fuel-cell operation, since the water activity is different and the water is present in both liquid and vapor form in the fuel cell, it does provide some indication of the membrane condition. The measured $\lambda$ values range from 14.1 to 16.3. These values are somewhat lower than for membranes that have not been hot-pressed. This may reflect some irreversible shrinkage of the ion clusters during the MEA fabrication and agrees very well with the values reported by Zawodzinski et al. ${ }^{17,18}$ for membranes that are dried at $105^{\circ} \mathrm{C}$ for $1 \mathrm{~h}$ and subsequently reimmersed in liquid water at $80^{\circ} \mathrm{C}$. This shows the membranes are reasonably well hydrated in the PEMFC, although the hot-pressing has lowered the water content a little. By modifying the hot-pressing procedure it may be possible to raise the proton conductivities of the membranes slightly in the MEAs.

The MEA performances in the internally humidified Ballard Mark 5E single cell with hydrogen as fuel and oxygen as oxidant are shown in Fig. 5. The role of the progressively thinner membrane materials in achieving higher single-cell performances is clear. The reduced ohmic resistance of the Nafion membrane results in a significantly reduced slope in the pseudolinear region of the cell potential vs. current density graphs.

The membrane resistance (together with any electrodemembrane contact resistance) at each current density in Fig. 5 can be separated from the total MEA resistance using the currentinterrupt technique, which does not include the bulk electrode resistances. ${ }^{41}$ The electronic resistance of the gas distribution plates and the Toray paper substrates is included, however, in the measurements. An electronic resistance of $0.045 \Omega \mathrm{cm}^{2}$ was estimated for these components in ex situ measurements using a two-point probe as described previously. The value was obtained from the flatter region of the electronic resistance $v s$. applied pressure graph, corresponding to the estimated applied pressure in the Ballard Mark 5E single cell of approximately $0.5-1 \mathrm{MPa}$ abs. It was not possible to be more precise regarding the applied pressure in the cell. The gas distribution plates are not solid and there are a number of plates, all with different designs, between the end plates where the load is applied in the single cell and the gas distribution plates sandwiching 


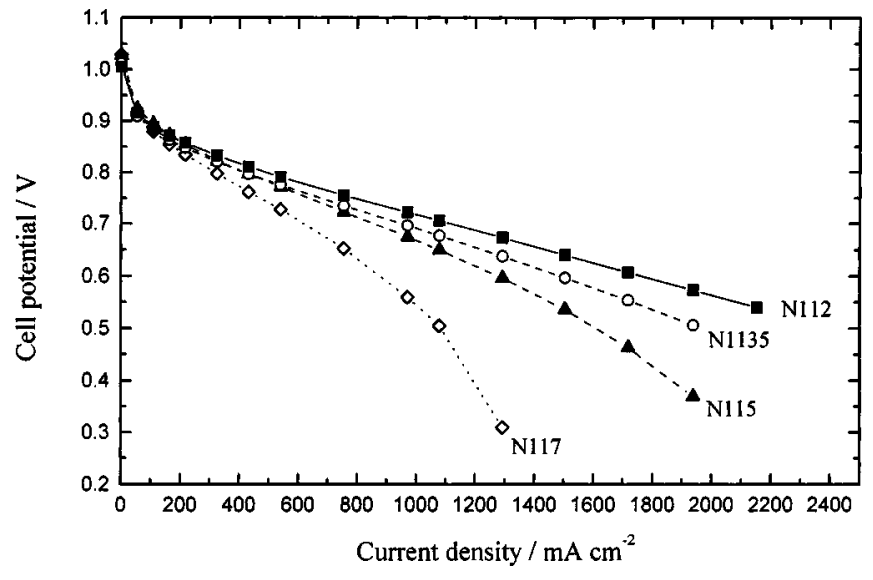

Figure 5. The MEA performances with the Nafion 1100 EW series of membranes in a Ballard Mark 5E single cell. The cell is at $80^{\circ} \mathrm{C}$ and is operating on $\mathrm{H}_{2} / \mathrm{O}_{2}$ at $300 \mathrm{kPa}$ abs and $1.5 / 10.0$ stoichiometry with full internal humidification.

the MEA. The electronic resistance of the hardware and the substrate corresponds to $27-48 \%$ of the total measured current-interrupt resistances.

Figure 6 shows the plots of the area resistances as a function of the current density measured in the Ballard Mark 5E single cell. The area resistances have not been corrected for the electronic resistance of the gas distribution plates and the Toray paper substrates in this case. Making this correction to obtain the membrane resistance and any membrane-electrode contact resistance would not have a significant effect on the shape of the plots in Fig. 6. The plots show the area resistance profiles are flat for the thinner membranes. As the membrane thickness is increased, however, the area resistance increases at higher current density, with the current density at which the area resistance starts to increase becoming progressively lower as the thickness of the membrane increases.

A mass balance for the water in the system supported the argument that this increase in the current-interrupt resistances at high current density with the thicker membranes was due to the anode face of the membrane drying. Weighing the water exiting the cathode and anode for defined time periods confirmed less water was exiting through the anode with the thicker Nafion membranes. Typically, at current densities above $500 \mathrm{~mA} \mathrm{~cm}^{-2}$, a net water flux of $0.020 \mathrm{H}_{2} \mathrm{O} / \mathrm{H}^{+}$was transported from anode to cathode for Nafion 112 , while $0.055 \mathrm{H}_{2} \mathrm{O} / \mathrm{H}^{+}$was transported for Nafion 117. Since the

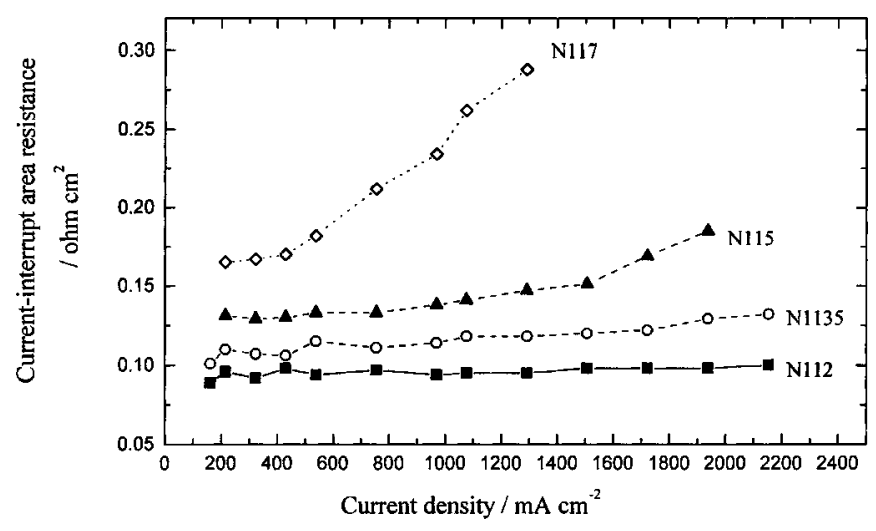

Figure 6. Area resistance measured by current-interrupt as a function of current density in the Ballard Mark 5E single cell. (Area resistance values include electronic cell resistance.) The cell is at $80^{\circ} \mathrm{C}$ and is operating on $\mathrm{H}_{2} / \mathrm{O}_{2}$ at $300 \mathrm{kPa}$ abs and $1.5 / 10.0$ stoichiometry with full internal humidification.

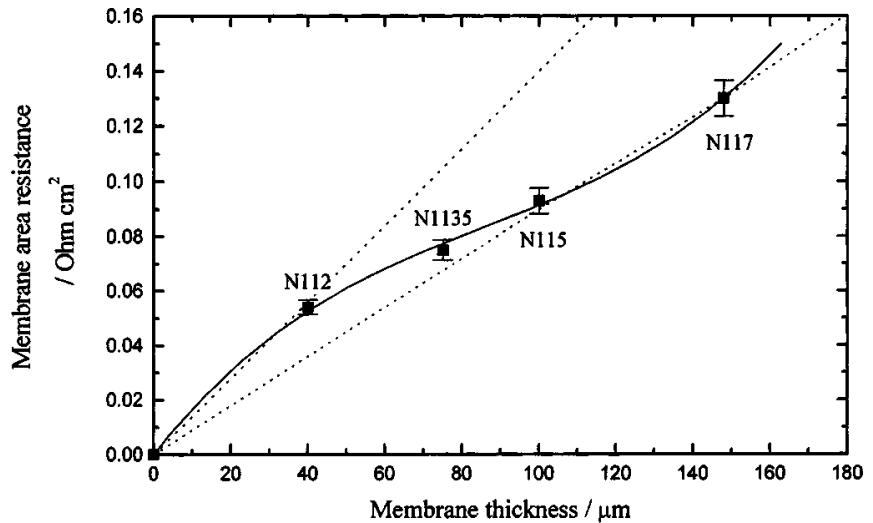

Figure 7. Membrane area resistance of the Nafion $1100 \mathrm{EW}$ series of MEAs operating at $538 \mathrm{~mA} \mathrm{~cm}^{-2}$ in the Ballard Mark 5E single cell as a function of the (dry) membrane thickness. (Membrane area resistance values have been corrected for electronic cell resistance.) The upper and lower dotted lines represent the projected ohmic behavior based on N112 and N117, respectively.

rate of electro-osmotic drag is essentially independent of membrane thickness (at a given $\lambda$ ), this showed that while the rate of water back-diffusion was close to the rate of electro-osmotic drag for both MEAs, it was $0.035 \mathrm{H}_{2} \mathrm{O} / \mathrm{H}^{+}$slower for Nafion 117 under the cell operating conditions. In this situation, drying of the anode membrane interface with the electrode is very likely with the thicker Nafion membranes at high current densities.

Based on a constant electro-osmotic drag and assuming the sole factor controlling water back-diffusion is membrane thickness, application of Fickian diffusion suggests the water back-diffusion should be 3.75 times faster through Nafion 112 . The net water fluxes suggest, however, that the relative rate of water back-diffusion is only about 2.75 times faster through Nafion 112. Along with the higher-than-predicted membrane resistance of Nafion 112 in the ex situ measurements, this points to a structural effect of the thinner Nafion membrane.

An important consequence of the MEA resistance and water balance measurements is confirmation that the resistance values in the flat regions of Fig. 6 reflect the resistance in a well-humidified membrane and are not indicative of a membrane with a particularly uneven water balance. Figure 7 shows the relationship between the membrane area resistances at $538 \mathrm{~mA} \mathrm{~cm}^{-2}$ (assuming a negligible electrode-membrane contact resistance) and the membrane thickness (stated on a dry membrane basis) in the MEAs. At this current density all area resistances are in the flat region of Fig. 6 for all Nafion membranes apart from Nafion 117, which shows evidence of slight anode drying. The membrane area resistances have been corrected for the ex situ electronic resistance of the gas distribution plates and the Toray paper substrate. As in the case of the ex situ data in $\mathrm{H}_{2} \mathrm{SO}_{4}$ the membrane area resistance increases with increasing membrane thickness but in a nonlinear fashion. Again, the area resistance of the thinner Nafion membranes is higher than predicted by Ohm's law. This is shown clearly in the resulting plots of conductivity and resistivity for the series of MEAs (Fig. 8). While electrode-membrane contact resistance could account for part of the nonlinearity, combined with the ex situ conductivity measurements, this does point to an effect of membrane structure. The practical consequence of this effect is that the full benefit expected from a reduction in the membrane thickness in Nafion 112 is not being translated to an improved ohmic response from the MEA during fuel-cell operation.

This nonlinear response from extruded Nafion membranes has been observed in the PEMFC by Paganin et al., ${ }^{42}$ who examined the performance of Nafion 117, 115, and 112 in a small single cell. They attributed the nonlinear response of the area cell resistance with the membrane thickness to an uneven water distribution in the mem- 


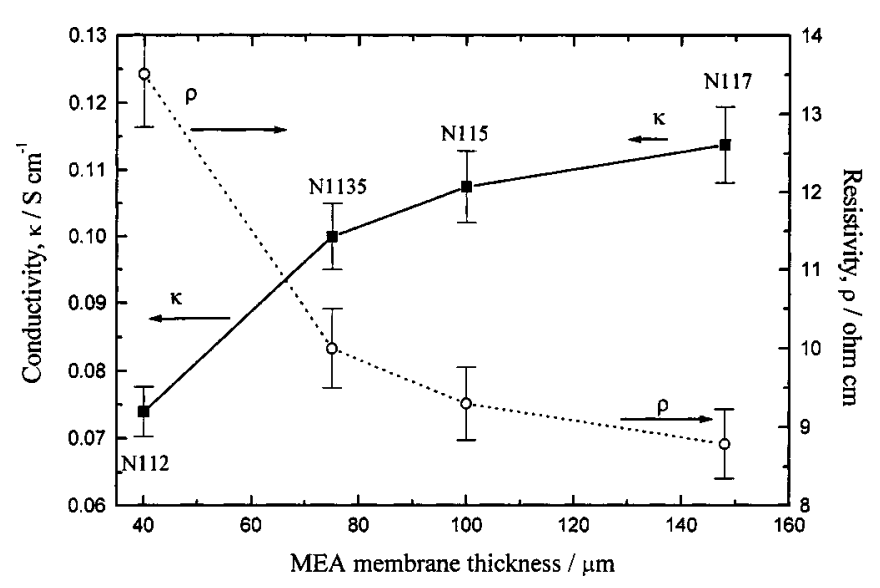

Figure 8. The variation in the conductivity and resistivity of the Nafion 1100 EW series of membranes with MEA (dry) membrane thickness measured in situ in the Ballard Mark 5E single cell using the current-interrupt technique $\left(538 \mathrm{~mA} \mathrm{~cm}^{-2}\right)$.

branes, which they argued was poorer in the thicker membranes. They did not, however, have the benefit of the current-interrupt measurements to isolate the membrane resistance, and they did not examine the MEA water balance in detail. As discussed previously a relatively poor performance from thinner membranes cannot easily be explained by an uneven water distribution. In any case, it is only at high current densities (beyond the pseudolinear region of the polarization curves examined by Paganin et al. ${ }^{42}$ ) that there is evidence of a significantly uneven water distribution in the thicker membranes.

During a recent study of the transversal water profile in Nafion membranes, ${ }^{43}$ Buchi and Scherer have reported on the dependence of the membrane resistivity (via the current-pulse method) on the membrane thickness for zero current conditions and PEMFC operation at $60^{\circ} \mathrm{C}$ using Nafion 112, 115, and 117 based MEAs. The resistivity was not constant with membrane thickness and increased from approximately 9.2 to $10.8 \Omega \mathrm{cm}$ as the membrane thickness decreased from 200 to $60 \mu \mathrm{m}$. Reasonably high water contents of $\lambda=13-14$ were measured for the membranes ex situ, in close accord with the values reported here

Figure 9 shows the conductivities measured ex situ for the membrane in the $\mathrm{H}_{2} \mathrm{SO}_{4}$ electrolyte and in situ for an MEA in the PEMFC. The membrane thickness is measured in the wet state for the ex situ results and in the dry state for the in situ ones. The in situ data in the PEMFC refers to averaged measurements made at a current density of $538 \mathrm{~mA} \mathrm{~cm}^{-2}$. It is clear that the relative trend in the conductivities with the membrane thickness is similar in the two systems.

These results clearly demonstrate a decrease in the membrane conductivity as the membrane thickness is reduced. The structure, for example, the porosity and the charge distribution in the membrane, as well as the water content must be significant factors to be considered when explaining the reasons for the observed reduction in the overall transport properties of the membrane. ${ }^{44}$

The observed decrease in conductivity with thickness in the present study is unlikely to be the result of markedly different water concentrations in the membrane. Nor is it likely to be due to inhomogeneities in the density distribution of sulfonic acid groups, since all membranes were fully hydrated and of approximately the same equivalent weight. Modifications in surface roughness would also be expected to alter the conductivity, as a smoother surface would reduce the overall surface area and probably the cluster density distribution. Although atomic force microscopy (AFM) measurements showed a marginal reduction of approximately $1 \mathrm{~nm}$ in surface roughness for the thinner membranes, ${ }^{45}$ this is insufficient to explain the observed variation in resistance.

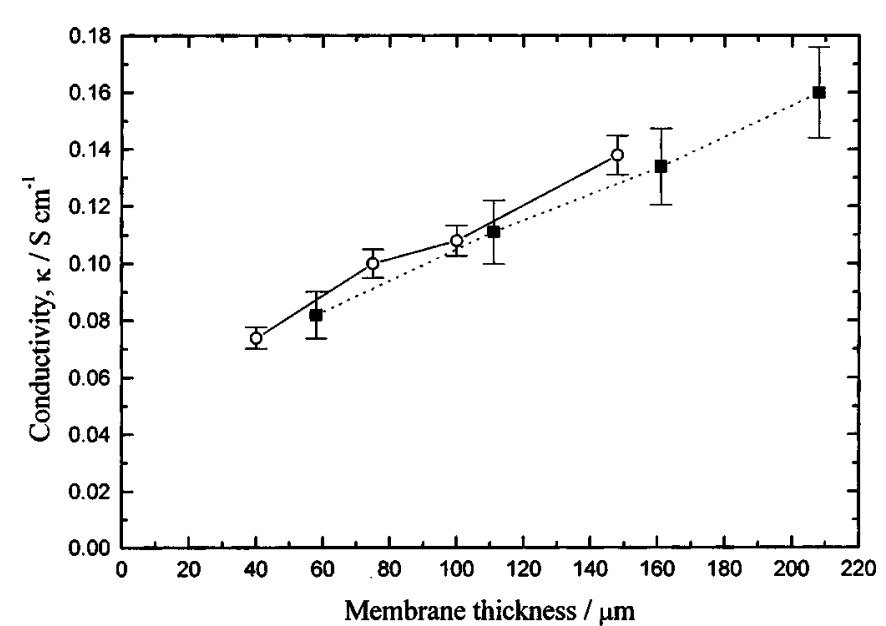

Figure 9. Comparison of the conductivity of the Nafion $1100 \mathrm{EW}$ series of membranes measured ex situ (immersed in $1 \mathrm{M} \mathrm{H}_{2} \mathrm{SO}_{4}$ at $25^{\circ} \mathrm{C}$ ) and in situ (in the Ballard Mark $5 \mathrm{E}$ single cell with humidified gases at $80^{\circ} \mathrm{C}$ ) where (-O-) represents the ex situ and (-口-) represents the in situ conductivity. Membrane thickness has been measured for dry material (in situ data) and for wet material (ex situ data).

Water and ion transport is known to be influenced by the channel-like microstructure of the Nafion membrane. The dimensions of the ion and associated water molecules, compared to that of the channel diameter, have been shown to have a major impact on ion mobility within the membrane. ${ }^{46}$ As the dimensions approach those of the channels, the membrane resistance is seen to decrease. ${ }^{46}$ Such observations are in agreement with the Gierke model, ${ }^{7}$ where all channels were assumed to be of a similar size.

The most likely explanation for the unexpected decrease in conductivity for thin membranes must be related to their production process. The membranes are prepared by extrusion; the temperatures and pressures must have a pronounced effect on the surface structure of the material. Thinner membranes may have been produced with a higher roller pressure, resulting in increased local temperature and the melt flow of surface layers, and in some closing of ion and water channels, reduction in their size, or an increase in their tortuosity.

Although no single theory is able to describe the transport of ions through Nafion, it appears that the membranes contain surface layers whose structure and hydrophobic and hydrophilic properties are very different from those of the "bulk" material. Swollen Nafion membranes have been found to contain troughs on the surface. ${ }^{47}$ The diffusion coefficient of water through Nafion suggests a dominant pore volume of $1-100 \mathrm{~nm}$. These pores are found in the interior of membrane with a small volume of larger pores associated with a rough outer surface. The high value of the inner surface charge density has been related to a small diffusivity of proton double layers inside pores. This suggests that the mobility of protons in the interior of the pores could be much higher than along the pore surface. Discontinuities in structure between the surface and "bulk" regions of the membrane are more important for thin membranes where the ratio of surface to "bulk" pores is greater. The results reported in this paper highlight the increasing importance of "skin" effects (relative to bulk effects) in thinner membranes.

Production techniques are critically important in realizing low MEA area resistance. In recent studies, we have modified membrane/electrode bonding techniques to provide lower area resistance values than those reported in this paper.

\section{Acknowledgments}

This work has been supported by an EPSRC CASE award to Sharon Slade. The authors are grateful to Johnson Matthey Technology Center for supply of materials, and to Dr. Des Barker for technical discussions. 
The Johnson Matthey Technology Center assisted in meeting the publication costs of this article.

\section{List of Symbols}

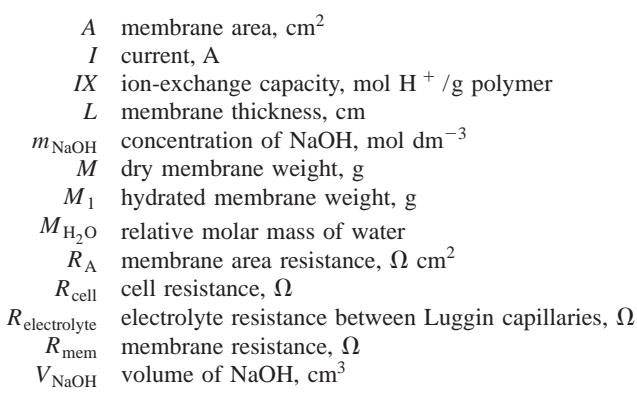

Greek

$\Delta E_{\text {ref }}$ potential difference between matched reference electrodes, $\mathrm{V}$

$\kappa$ membrane conductivity, $\mathrm{S} \mathrm{cm}^{-1}$

$\lambda$ water content, $\mathrm{mol} \mathrm{H} \mathrm{H}_{2} \mathrm{O} / \mathrm{mol} \mathrm{SO}_{3} \mathrm{H}$

$\rho$ membrane resistivity, $\Omega \mathrm{cm}$

\section{References}

1. O. Savadogo, J. New Mater. Electrochem. Syst., 1, 47 (1998).

2. F. C. Walsh, A First Course in Electrochemical Engineering, The Electrochemical Consultancy, Romsey, U.K. (1993).

3. D. Pletcher, A First Course in Electrode Processes, The Electrochemical Consultancy, Romsey, U.K. (1991).

4. T. A. Davies, J. D. Genders, and D. Pletcher, Ion Permeable Membranes, The Electrochemical Consultancy, Romsey, U.K. (1997).

5. T. R. Ralph, Platinum Met. Rev., 41, 102 (1997).

6. T. R. Ralph and G. A. Hards, Chem. Ind., 1998, 337.

7. T. D. Gierke and W. S. Hsu, in Perflourinated Ionomer Membranes, A. Eisenberg and H. L. Yeager, Editors, p. 283, ACS Symposium Series 180, American Chemical Society, Washington, DC (1982).

8. M. Eikerling, A. A. Kornyshev, and U. Stimming, J. Phys. Chem. B, 101, 10807 (1997).

9. H. L. Yeager, in Perflourinated Ionomer Membranes, A. Eisenberg and H. L. Yeager, Editors, ACS Symposium Series 180, American Chemical Society, Washington, DC (1982).

10. A. Eisenberg, Macromolecules, 3, 147 (1970).

11. K. A. Mauritz, C. J. Hora, and A. J. Hopfinger, in Ions in Polymers, Advances in Chemistry Series, A. Eisenberg, Editor, Chap. 8, American Chemical Society, Washington, DC (1980).

12. S. Gottesfeld and T. A. Zawodzinski, in Polymer Electrolyte Fuel Cells, Advances in Electrochemical Science and Engineering, Vol. 5, p. 245, Wiley, New York (1997).

13. P. C. Reike and N. E. Vanderborgh, J. Membr. Sci., 32, 313 (1987)

14. M. Verbrugge and R. Hill, J. Electrochem. Soc., 137, 3770 (1990).

15. M. Verbrugge, E. W. Schneider, R. S. Conell, and R. Hill, J. Electrochem. Soc., 139, 3421 (1992).

16. T. A. Zawodzinski, M. Neeman, L. O. Sillerud, and S. Gottesfeld, J. Phys. Chem., 95, 1040 (1991).
17. T. A. Zawodzinski, C. Derouin, S. Radzinski, R. J. Sherman, V. T. Smith, T. E. Springer, and S. Gottesfeld, J. Electrochem. Soc., 140, 1041 (1993).

18. T. A. Zawodzinski, T. E. Springer, J. Davey, R. Jestel, C. Lopez, J. Valerio, and S. Gottesfeld, J. Electrochem. Soc., 140, 1981 (1993).

19. T. A. Zawodzinski, T. E. Springer, F. Urtribe, and S. Gottesfeld, Solid State Ionics, 60, 199 (1993).

20. J. R. Perez, M. Lopez-Atalaya, G. Codina, J. L. Vazquez, and A. Aldaz, Bull. Electrochem., 7, 559 (1991).

21. J. A. Kolde, B. Bahar, M. S. Wilson, T. A. Zawodzinski, and S. Gottesfeld, in Proton Conducting Membranes Fuel Cells, S. Gottesfeld, G. Halpert, and A. Landgrebe, Editors, PV 95-23, p. 193, The Electrochemical Society Proceedings Series, Pennington, NJ (1995).

22. J. Halim, F. N. Buchi, O. Haas, M. Stamm, and G. G. Scherer, Electrochim. Acta, 39, 1303 (1994)

23. K. M. Nouel and P. S. Fedkiw, Electrochim. Acta, 43, 2381 (1998).

24. M. Yoshitake, M. Tamura, N. Yoshida, and T. Ishisaki, Denki Kagaku, 64, 727 (1996).

25. N. Yoshida, T. Ishisaki, A. Watanabe, and M. Yoshitake, Electrochim. Acta, 43, 3749 (1998).

26. A. V. Anantaraman and C. L. Gardner, J. Electroanal. Chem., 414, 115 (1996).

27. Y. Sone, P. Ekdunge, and D. Simonsson, J. Electrochem. Soc., 143, 1254 (1996).

28. J. J. Sumner, S. E. Creager, J. J. Ma, and D. D. DesMarteau, J. Electrochem. Soc., 145, 107 (1998).

29. C. A. Edmondson, P. E. Stallworth, M. C. Wintersgill, J. J. Fontanella, Y. Dai, and S. G. Greenbaum, Electrochim. Acta, 43, 1295 (1998).

30. M. Wakizoe, O. A. Velev, and S. Srinivasan, Electrochim. Acta, 40, 335 (1995).

31. F. N. Buchi and G. G. Scherer, J. Electroanal. Chem., 404, 37 (1996).

32. W. Grot, G. E. Munn, and P. N. Walmsley, Abstract, 154, p. 394, The Electrochemical Society Extended Abstracts, Vol. 72-1, Houston, TX, May 7-11, 1972.

33. K. D. Kreuer, T. Dippel, and J. Maier, in Proton Conducting Membrane Fuel Cells, S. Gottesfeld, G. Halpert, and A. Landgrebe, Editors, PV 95-23, p. 241, The Electrochemical Society Proceedings Series, Pennington, NJ (1995).

34. T. R. Ralph, G. A. Hards, J. E. Keating, S. A. Campbell, D. P. Wilkinson, M. Davis, J. St-Pierre, and M. C. Johnson, J. Electrochem. Soc., 144, 3845 (1997)

35. F. N. Buchi, A. Marek, and G. G. Scherer, J. Electrochem. Soc., 142, 1895 (1995).

36. E. A. Ticianelli, C. R. Derouin, and S. Srinivasan, J. Electroanal. Chem., 251, 275 (1988).

37. J. Denton, J. Gascoyne, and D. Thompsett, U. S. Pat. 5,716,437 (1998).

38. K. Prater, J. Power Sources, 51, 129 (1994).

39. C. L. Gardner and A. V. Antanaraman, J. Electroanal. Chem., 449, 209 (1998)

40. G. Pourcelly, A. Oikonomou, C. Gavach, and H. D. Hurwitz, J. Electroanal. Chem., 287, 43 (1997).

41. T. R. Ralph, in Proceedings of Fuel Cell Seminar, Palm Springs, CA, Nov 16-19, 1998.

42. V. A. Paganin, E. A. Ticianelli, and E. R. Gonzalez, in Proton Conducting Membrane Fuel Cells, S. Gottesfeld, G. Halpert, and A. Landgrebe, Editors, PV 95-23, p. 102, The Electrochemical Society Proceedings Series, Pennington, NJ (1995).

43. F. N. Buchi and G. G. Scherer, J. Electrochem. Soc., 148, A183 (2001).

44. A. Lehmani, P. Turq, M. Perie, J. Perie, and J. P. Simonin, J. Electroanal. Chem., 428, 81 (1997).

45. S. Slade, J. Smith, S. A. Campbell, F. C. Walsh, and T. R. Ralph, Unpublished.

46. T. Okada, G. Xie, O. Gorseth, S. Kjelstrup, N. Nakamura, and T. Arimura, Electrochim. Acta, 43, 3741 (1998).

47. J. Divisek, M. Eikerling, H. Schmitz, U. Stimming, and Y. M. Volfkovich, J. Electrochem. Soc., 145, 2677 (1998). 